
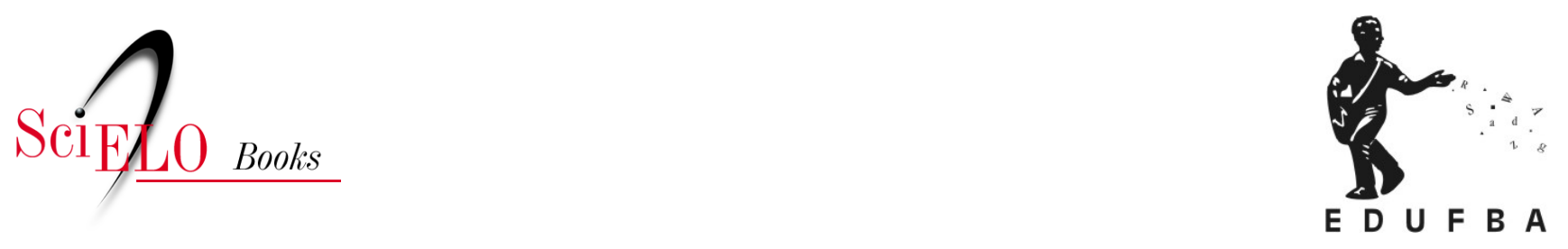

\title{
Política nacional de saúde bucal (PNSB) de 1989
}

\author{
Thais Regis Aranha Rossi
}

\section{SciELO Books / SciELO Livros / SciELO Libros}

ROSSI, T.R.A. Política nacional de saúde bucal (PNSB) de 1989. In: Produção social das políticas de saúde bucal no Brasil [online]. Salvador: EDUFBA, 2018, pp. 93-110. ISBN 978-85-232-2022-8. https://doi.org/10.7476/9788523220228.0005.

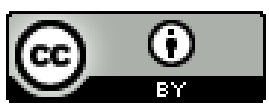

All the contents of this work, except where otherwise noted, is licensed under a Creative Commons Attribution 4.0 International license.

Todo o conteúdo deste trabalho, exceto quando houver ressalva, é publicado sob a licença Creative Commons Atribição 4.0. 


\section{POLÍTICA NACIONAL DE SAÚDE BUCAL (PNSB) DE 1989}

Em outubro de 1988, em Brasília, foi lançado o primeiro documento intitulado Política Nacional de Saúde Bucal, com publicação oficial no ano de 1989 (Figura 4), remetendo a um conceito de Atenção Básica em Saúde Bucal como

O conjunto de ações orientadas à identificação, prevenção e solução dos principais problemas da população afetada, a qual se produz como o fruto da participação consciente e organizada da comunidade e de sua cooperação com as instituições de saúde. (BRASIL, 1988)

Foi, porém, entendido como sinônimo de ações essenciais destinadas ao alívio da dor e controle de infecção em grupos epidemiologicamente prioritários. Embora fosse denominada de Política Nacional de Saúde Bucal, o objetivo principal da política era enfrentar o problema cárie. Assim, o Sistema de Saúde buscaria se organizar para:

- alcançar ampla cobertura das crianças de 6 a 12 anos;

- prevenir as doenças bucais, com ênfase na cárie dental, em toda a população, a partir do nascimento;

- enfatizar ações de educação para a saúde bucal, em todos os níveis;

- prestar cuidados essenciais onde houvesse uma comunidade;

- prestar atenção especializada a casos encaminhados pela rede básica de saúde bucal; e

- expandir, gradativamente, a prestação de serviços resolutivos aos grupos em segundo e terceiro graus de prioridade - 13 a 19 anos e 2 a 5 anos de idade. 
O objetivo geral da política aprovada ${ }^{44}$ pela Portaria no 613/GM, de 13 de junho de 1989, foi "proporcionar melhores níveis de saúde bucal à população brasileira e ampliar o acesso aos serviços odontológicos disponíveis” (BRASIL, 1989b), entretanto, observou-se um objeto de trabalho predominantemente voltado aos dentes e à cárie dentária.

Os objetivos específicos da política tratavam de:

- reduzir em $50 \%$ a prevalência de cárie dental em crianças e adolescentes no prazo de dez anos;

- combater as doenças periodontais, aumentando os índices de higidez em todas as faixas etárias;

- reduzir significativamente os índices de edentulismo e o número de extrações na população jovem e adulta;

- democratizar o acesso aos serviços odontológicos por meio do aumento da oferta, da atenção a grupos prioritários e da ampla participação da comunidade;

- estruturar uma rede nacional de serviços básicos em saúde bucal;

- promover ações continuadas de educação para a saúde bucal, de forma a nortear todas as atividades do setor; e

- apoiar a formação de recursos humanos de nível superior, técnico e auxiliar compatíveis com o quadro epidemiológico, com a situação econômico social e com os padrões de crescimento populacional do país. (BRASIL, 1989b)

Apesar de constar no documento a sua construção pelas entidades de saúde pública e representativas de classe, além das seis Macro-coordenadorias Regionais de Odontologia, fundamentada na experiência adquirida ao longo dos anos e de

44 Na minuta de aprovação do referido documento constam: (i) Vitor Gomes Pinto - diretor da Divisão Nacional de Saúde Bucal (SNPES)/Ministério da Saúde; Osdyr Brasileiro de Matos: coordenador de Supervisão e Auditoria de Odontologia - Inamps/ MPAS; Celso Fetter Hilgert: secretário nacional de Programas Especiais/MS; João José Candido da Silva: coordenador especial de Ciências da Saúde - Secretaria de Ensino Superior/ MEC; Nicolau Tortamano: presidente da ABO; Osmar Soares de Freitas: presidente do CFO; Gregório Abner Cabral: presidente da Federação Nacional de Odontologia; Edrízio Barbosa Pinto: presidente da Associação de Ensino Odontológico; Charlei Fayal de Lira: presidente da Academia Brasileira de Odontologia; Maria Aurinalva Lobão: coordenadora macro-regional de Odontologia do Norte; Tereza Marluce Rocha Tavares: coordenadora macro-regional de Odontologia/Nordeste I; Dorielio Barreto da Costa: coordenador macro-regional de Odontologia/Nordeste II; José Abel Porto Almeida: coordenador macro-regional de Odontologia Centro-Oeste; Urubatã Madeiros Vieira: coordenador macro-regional de Odontologia Sudeste; e Djalmo Sanzi Souza: coordenador macro-regional de Odontologia do Sul. 
um sólido processo de construção democrática, Zanetti (1993) afirma que as prioridades programáticas foram definidas a partir das proposições da VII CNS e não contou com um debate setorial amplo.

A plenária do MBRO, de 28 de janeiro de 1989, tratava que, historicamente, as entidades de classe aprovavam todas as iniciativas dos governos das elites; afirmava ser inaceitável que a tão reclamada política não contasse com a participação dos trabalhadores, estudantes, usuários dos serviços; e acusava a PNSB de tão ilegítima quanto o próprio governo Sarney; ademais, apontavam que o documento ignorava as deliberações da I CNSB. (ZANETTI, 1993)

A formulação foi muito coordenada pelo Vitor Pinto, com uma participação do Sylvio Gevaerd com a discussão com coordenadores de macrorregião. Consulta a essas pessoas, mas ela ficou enquistada no ministério. Ela não teve uma repercussão nacional [...]. (Entrevistado 7, dentista, consultor)

A política era uma reivindicação antiga da categoria, da categoria de saúde pública, dos coordenadores estaduais, municipais, do pessoal que fazia saúde pública na época. O Brasil é pioneiro no mundo ocidental, principalmente nos países em desenvolvimento, nós éramos copiados pela América Latina e pelos outros. (Entrevistado 12, dentista, escritor)

As distintas tomadas de posição sobre a política podem ser analisadas segundo as trajetórias dos agentes. Entrevistado 7 graduou-se em Odontologia, em 1971, concluiu especialização em Odontologia Preventiva e Social, em 1979. Seu pai era dentista e seus avós comerciante e funcionário público. Tinha disposições políticas, sendo filiado a partido político, o PMDB. Entrevistado 12 formou-se em Odontologia em 1965, mestrado em Saúde Pública, em 1977. Seu pai era serventuário da justiça, seu avô materno era jornalista; desconhece a profissão dos avós paternos. Não possuía filiação a partidos políticos, apresentando pequena disposição política. O Entrevistado12 apresentava maior acumulação de capital burocrático e científico que Entrevistado 7, que, por sua vez, apresentava capital burocrático mediano e maior capital político que Entrevistado 12.

Os serviços deveriam se organizar também por prioridades. Os serviços emergenciais eram para todos e deveriam preceder os demais; em segunda prioridade, as ações preventivas e de educação em saúde; em terceiro lugar, "serviços recuperadores básicos” como atenção à cárie e doença periodontal, ao grupo de 6 a 12 anos; em quarta escala estariam as especialidades básicas para atenção endodôntica, periodôntica, protética, cirúrgica e ortodôntica para os grupos de 6 a 12 anos e 13 
a 19 anos participantes de um sistema organizado; e na quinta posição, serviços especializados de maior complexidade. Não ficaram claras as condições utilizadas para a definição dos serviços citados. A coordenação política nacional do setor seria da DNSB com o apoio da Coordenadoria de Supervisão e Auditoria de Odontologia do Inamps. (BRASIL, 1988)

O Entrevistado 12 afirmou que o processo de construção da política exigiu etapas, como a formulação de um documento inicial, assim como recebeu muitas críticas quando estava na DNSB. A política se baseou nos conhecimentos de saúde pública praticados até então, preconizados por Mário Chaves e Alfredo Reis Viegas. Não trazia inovações do ponto de vista científico, tendo se baseado no sistema incremental. Incorporava diretrizes do processo da reforma sanitária, como universalização, participação da comunidade, hierarquização, regionalização e integração institucional, mas não abordava como operacionalizá-la quanto aos problemas sociais construídos relativos a doenças bucais.

Observa-se que o documento da política buscava responder ao inquérito epidemiológico de 1986, que estabelecia como prioridades a cárie e a doença periodontal. Uma comissão assessorava o Diretor da Divisão Nacional de Saúde Bucal do Ministério da Saúde, Vitor Gomes Pinto, que já havia participado da comissão de especialistas para editar o documento anterior no âmbito da Previdência.

O V Enatespo, realizado de 23 a 26 de agosto de 1988, reafirmou o projeto da Reforma Sanitária Brasileira, as conclusões da VIII CNS e da I CNSB. O relatório tratou que as conclusões da I CNSB divergiram da primeira política de saúde bucal.

As críticas perpassaram os seguintes aspectos:

- a plenária final da I CNSB recomendou a criação de um Conselho Nacional de Saúde Bucal com representantes estaduais e municipais para formulação da Política e deliberar sua implementação, sendo que este Conselho não foi formalmente criado;

- advertiu a elaboração de pacotes inadequados às realidades locais;

- defendeu o processo de descentralização pelo fortalecimento da municipalização; e

- criticou as entidades de classe contrárias à extinção do cargo de odontologia do Inamps, explicando que este era um passo para a consolidação do SUDS. (ENATESPO, 1988)

Em 13 de junho de 1989, foi publicada portaria que instituía o grupo de especialistas em prevenção de doenças bucais que era composto por Alfredo Reis Viegas, 
da USP, Osvaldo Carro Buendia, da Secretaria de Estado da Saúde de São Paulo e que trabalhava com o tema flúor, Jaime Aparecido Cury, professor da Universidade de Campinas (Unicamp) e que também desenvolvia trabalhos sobre flúor, Milton Fernando de Andrade Silva, da Universidade Federal de Alagoas (UFAL), Tania Maria Drehmer, da Universidade Federal do Rio Grande do Norte (UFRN), Leo Kriger, da Universidade Federal do Paraná (UFPR), Marisa Maltz, da Universidade Federal do Rio Grande do Sul (UFRGS) e Yvonne Buischi, então presidente da Aboprev.

A maioria dos consultores pertencia ao campo científico, com exceção de Osvaldo Carro Buendia que pertencia ao campo burocrático. Destaca-se que Alfredo Reis Viegas era professor com grande capital simbólico e científico da FSP/USP. Os outros consultores foram convidados pela expertise no campo científico em temas como cariologia, flúor, Odontologia Sanitária e Odontologia Preventiva.

A Aboprev foi objeto de estudo de Soares (2014). A autora abordou que, na década de 1980, a instituição desempenhou papel importante na fundação do espaço da Odontologia Preventiva e Social.

Figura 4 - Capa do documento de publicação da Política Nacional de Saúde Bucal, 1989

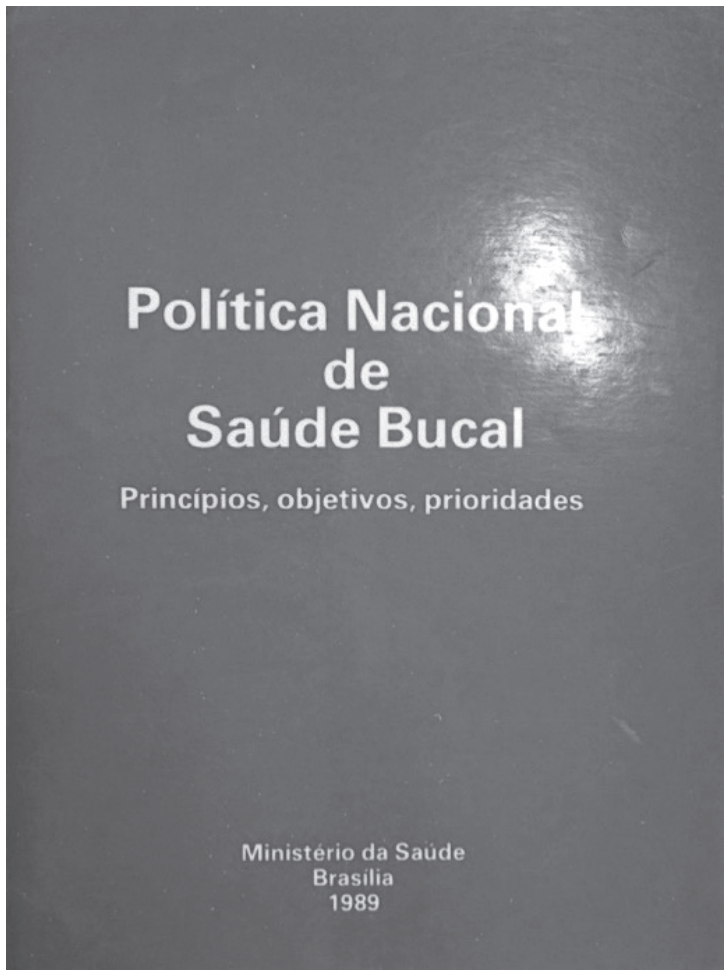

Fonte: Brasil (1989b).45

Cedido pelo Dr. Vitor Gomes Pinto. 
Hamilton Belinni, periodontista e professor da Unicamp, teve o apoio de Alfredo Reis Viegas e de outros colegas de profissão. Bellini agregou alguns dentistas na criação, com o nome inicial de Abrava, ${ }^{46}$ da qual Paulo Capel e Carlos Botazzo também participaram. A Abrava depois passou a se chamar a Aboprev. A prof ${ }^{\text {. }}$ Yvonne Buischi assumiu a presidência da Aboprev, no final da década de 1980, e é considerada por levar as propostas da instituição ao Brasil inteiro. A instituição cresceu por apresentar aspectos da prevenção também no âmbito privado, não apenas na saúde pública. Jaime Cury participou da Diretoria de Normas e Produtos e trouxe muitas contribuições sobre o flúor assim como na formulação das políticas de saúde bucal. A Aboprev organizou vários eventos científicos, criou sua própria revista e consolidou-se no campo científico, o que contribuiu para a sua influência no campo burocrático. (SOARES, 2014)

O Comitê Técnico Científico da Aboprev apoiava o processo decisório da Divisão do MS, a partir do acúmulo de capital científico pelos professores em diversas áreas.

Era o Alfredo Reis Viegas, o Jaime Cury, o Milton Fernando de Alagoas, a Ivone Buischi e Oswaldo Buendía, que era o cara do flúor. Esses estavam sempre nos apoiando. Esses eram a base de conhecimento científico, eram esses e principalmente o Viegas. (Entrevistado 12, dentista, escritor)

O Programa Nacional de Prevenção da Cárie Dental (Precad) (Figura 5), publicado no mesmo ano, tinha como objetivo geral reduzir em dez anos, 50\% da cárie dentária na população brasileira. A proposta era atingir o máximo de pessoas possíveis. Os subprogramas eram:

- fluoretação de água de consumo público;

- uso tópico de fluoretos;

- opção pela adoção de géis fluoretados aplicados em moldeiras na época das campanhas de vacinação, para atingir o máximo de pessoas;

- vigilância e controle - normas para controle e registro de produtos;

- formação de recursos humanos; e

- estudos epidemiológicos e biológicos. 
O Precad foi um desdobramento da primeira política e trazia planos mais detalhados de como combater a cárie dentária na década de 1980. Este programa foi bastante combatido, pois não existiam evidências científicas das melhorias da utilização do flúor em gel em crianças em detrimento das soluções fluoradas. Optou-se pela fluoretação com gel em moldeiras para crianças nas épocas de vacinação. Não houve consenso e o coordenador solicitou a aprovação no intuito de tratar a fluoretação de massas como alternativa semelhante aos mutirões de vacinas.

Zanetti (1993) traz evidências de que o método da fluoretação tópica pelos géis foi fruto da experiência do Serviço Social do Comércio (SESC)/DF com o "Método Carrossel”, que preconizava a fluoretação tópica de flúor gel em massa, através do qual era possível realizar 1.500 aplicações diárias, meta difícil de ser alcançada anteriormente com outros meios.

A citação traz as disputas no espaço. A oposição é entre o técnico e o político. Mas há também a oposição de dentistas do campo científico, consultores que pesquisavam o flúor, assim como alguns dentistas que representavam suas macrorregiões, pertencentes ao campo burocrático, que também foram contrários à utilização do método da fluoretação tópica através de moldeiras.

Figura 5 - Capa do documento de divulgação do Precad, 1989

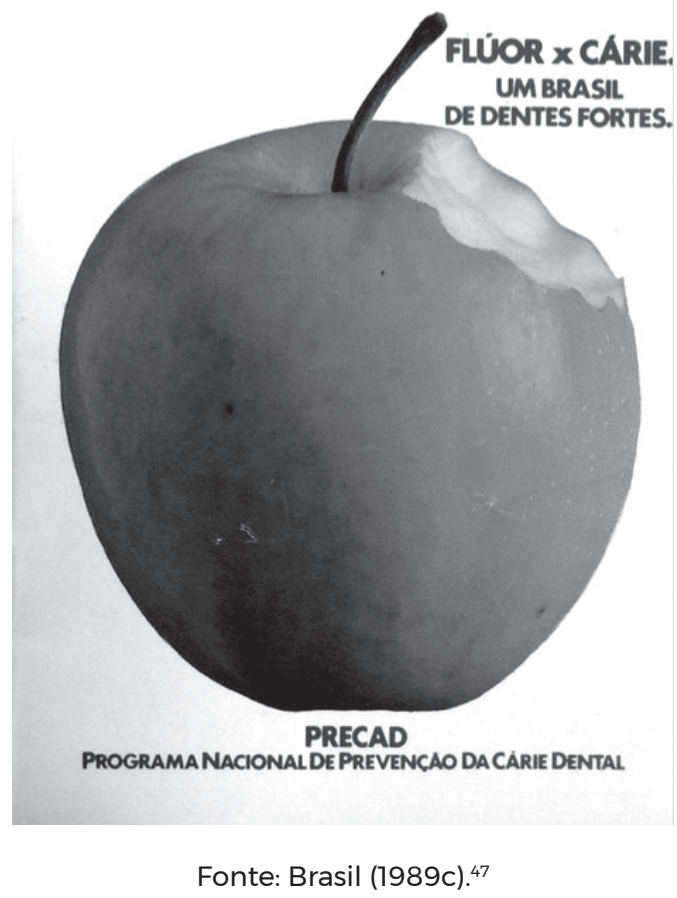

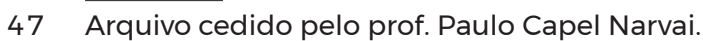


Conforme já citado, em 13 de junho de 1989, foi publicada a Portaria nº 614/ GM que estabeleceu o grupo de especialistas em prevenção de doenças bucais para assessorar a DNSB e apoiar as Unidades Federadas em seus programas, no intuito de reduzir o índice das enfermidades na população brasileira. Poucos dias depois, foi editada a Portaria de $n^{\circ} 616 /$ GM, de 23 de junho de 1989, que tratava da conformação de coordenadorias estaduais para apoio às políticas regionais e participação nas discussões nacionais, mas não definia nomes para compor essas coordenadorias.

Em seguida, em resposta às reivindicações dos movimentos sociais, das associações de classe e aos relatórios finais dos Enatespo, foi criado um comitê consultivo para a política.

\section{Regulamentação específica para fluoretação nos cremes dentais e enxaguatórios}

Outra resposta aos problemas bucais foi a fluoretação dos cremes dentais e, posteriormente, dos enxaguatórios bucais. Após a formação do comitê de especialistas, Jaime Cury, dentista e professor e pesquisador da área de flúor, trabalhou junto à DNSB para regulamentar os teores de flúor nos produtos utilizados pela população. A exemplo de outros países que haviam reduzido cárie, o Brasil também seguiu nesta linha para o combate à carie e o incentivo à prevenção.

Com as novas eleições presidenciais, foi eleito Fernando Collor de Melo como novo presidente da República. Vitor Gomes Pinto, com inserção predominante no campo burocrático, fez um documento ao novo ministro de Saúde, Alcenir Guerra, do novo governo, para permanecer na DNSB baseado em:

- estruturação de uma rede de serviços básicos;

- expansão e consolidação de um programa preventivo; e

- educação em saúde bucal com ênfase na autoproteção. (PINTO, 1990)

O documento datado de 15 de março de 1990 é iniciado com uma breve caracterização dos principais problemas bucais da população brasileira, do quadro de recursos humanos e da situação da rede pública de serviços. (PINTO, 1990)

A mãe do novo presidente tinha um dentista do qual era muito amiga e tinha relação de proximidade entre as famílias, Sergio Weyne que se tornou o novo coordenador de Saúde Bucal do Brasil, a partir de 1991. 


\section{O espaço de formulação e crítica das políticas de saúde bucal}

O espaço de formulação das políticas de saúde bucal, no período do final da década de 1980, foi formado pelos dentistas que participaram do processo de escrita, discussão e aprovação da política, mas, também, por aqueles que se organizavam para a realização de críticas que influenciavam a resposta do Estado. $\mathrm{O}$ principal problema construído nesse processo foi a doença cárie, a despeito da denominação "saúde bucal".

Estava em jogo quais seriam as melhores estratégias para o controle da cárie, o papel da DNSB, as práticas do cirurgião dentista, o mercado de trabalho, os interesses liberais, a formação profissional, pessoal auxiliar, estratégias de combate à cárie e a inserção da Odontologia na reestruturação do Sistema de Saúde do Brasil. A conformação deste espaço incluía agentes com inserção em distintos campos sociais. A Política Nacional de Saúde Bucal, de 1989, foi motivada pelas críticas à ausência de uma "política nacional de Odontologia" (ESTÁ..., 1982, p. 5) e teve início na convergência de interesses e trajetórias de agentes do campo burocrático com o apoio daqueles do campo científico vinculados à Faculdade de Saúde Pública da USP.

O espaço de formulação da política correspondia a uma intersecção dos campos político, científico e burocrático. As inserções predominantes dos $\mathrm{CD}$ desse espaço eram vinculadas ao campo burocrático, seguido dos consultores, que apresentavam inserção no campo científico. O diretor da DNSB possuía mestrado, mas seguia carreira com inserção predominante no campo burocrático. Dentre aqueles que participavam da gestão da DNSB ou desempenhavam papel como consultores da Divisão, a maioria apresentava baixo capital político, sem filiação a partidos políticos no momento, mas atuantes em associações corporativas (Quadros 7, 8 e 9). Os consultores se destacavam pelo capital científico e sua inserção neste campo, entretanto, existiam aqueles com inserção no campo burocrático, também (Quadros 7 e 8).

Os cirurgiões-dentistas que criticavam as políticas de saúde bucal através de movimentos organizados como o MBRO e os Enatespo, atuavam no campo burocrático, em esferas estaduais ou municipais, mas também existiam aqueles que pertenciam ao campo científico. A maioria deles era vinculada a partidos políticos de esquerda, figurava dentre os agentes com maior capital político e militavam em instituições pela Reforma Sanitária Brasileira, como o Cebes. Sua maior interseção com o espaço da política de saúde bucal se deu através do campo político, naquele momento. O polo dominante era exercido por agentes inseridos no campo burocrático, principalmente por profissionais oriundos da FSP/USP, assim como alguns consultores. 
O ponto de vista das instituições e das entidades de classe foi analisado a partir das tomadas de posições de seus participantes, mas representado enquanto microcosmo da instituição composta por seus agentes como a ABO e o CFO que apresentavam tomadas de posição relacionadas à Odontologia Liberal.

A ruptura com os interesses liberais e de mercado e as práticas odontológicas vigentes conformou um subespaço contra hegemônico de agentes identificados e partícipes do processo da Reforma Sanitária Brasileira.

As maiores acumulações de capital estiveram relacionadas à gestão da DNSB, aos consultores ligados à Aboprev e à FSP/USP. Dois membros que participavam dos Enatespo e MBRO também apresentavam grande volume de capital, um deles com trajetória no campo científico e o outro no campo burocrático estadual. Ambos tinham grande acumulação de capital político. Os outros membros desses movimentos apresentavam baixo ou médio volume de capital global.

Os agentes que influenciaram a formulação das políticas de saúde bucal ao final da década de 1980 eram predominantemente homens, de 25 a 60 anos no período. Há diferenças geracionais dentre as distintas posições ocupadas. Os representantes das entidades de classe, os membros do IPEA, a direção da DNSB e alguns consultores que realmente influenciaram o desenho da política, como Alfredo Reis Viegas, pertenciam a duas gerações de sanitaristas ligados à Odontologia Sanitária/Social.

Em geração intermediária, encontram-se alguns consultores, principalmente vinculados à Aboprev, assim como alguns membros do MBRO, fundadores do movimento. Ademais, os mais jovens pertenciam a esse subespaço de crítica.

O documento foi construído no interior do campo burocrático com o apoio de alguns consultores. Não houve consenso pela aprovação da política no grupo de consultores, segundo os entrevistados. As entidades de classe, como o CFO e a $\mathrm{ABO}$, se opuseram, inicialmente, à aprovação da política, devido às críticas à inclusão de pessoal auxiliar. A vertente dominante da Odontologia Sanitária defendia o uso do pessoal auxiliar, por sua vez extremamente combatida pelas entidades de classe que acreditavam representar uma ameaça aos postos de trabalho e ao papel do cirurgião-dentista no país. Já o MBRO acusava a DNSB de ilegítima assim como apontava a inconformidade da política com as deliberações da I CNSB.

Os dentistas com inserção no campo burocrático possuíam pós-graduação, mestrado ou especialização, em Saúde Pública. Os consultores apresentaram capital escolar alto, muitos deles com doutorado. Já dentre os membros do MBRO, a distribuição do capital escolar foi distinta, mas predominaram os agentes com especialização em Saúde Pública pela USP. 


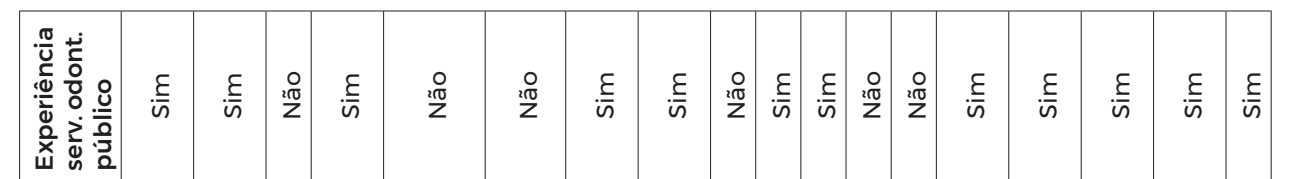

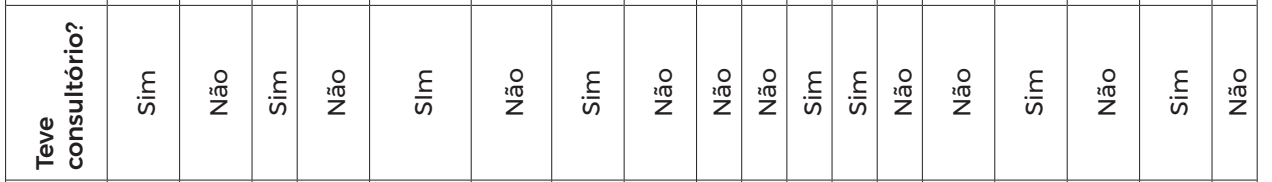

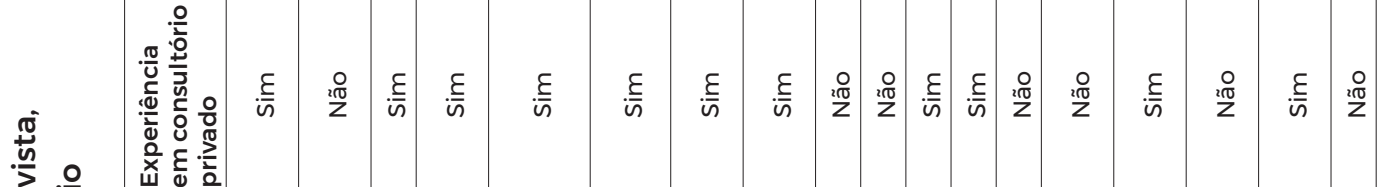

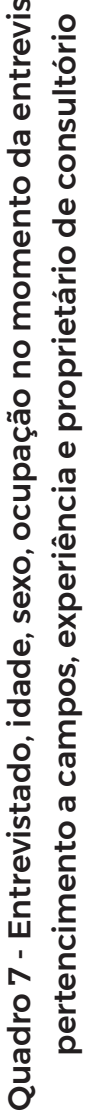

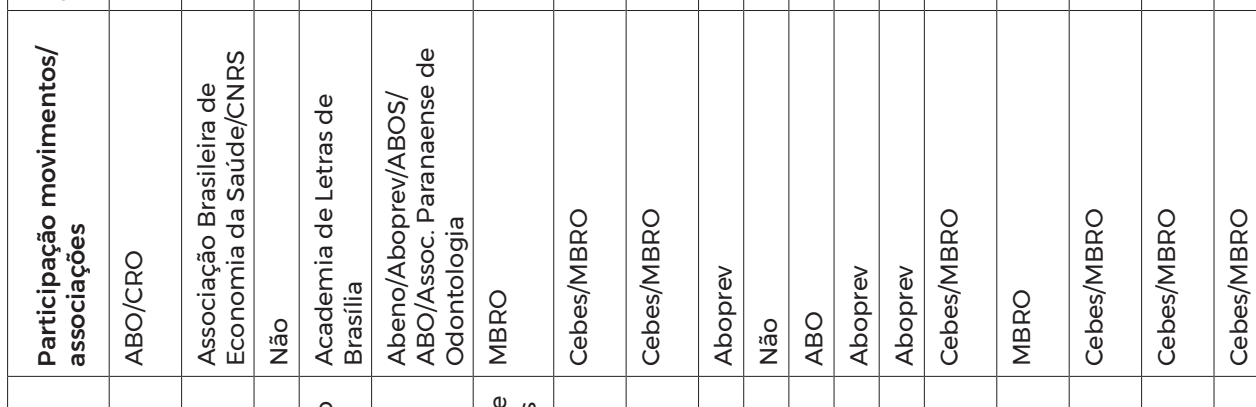

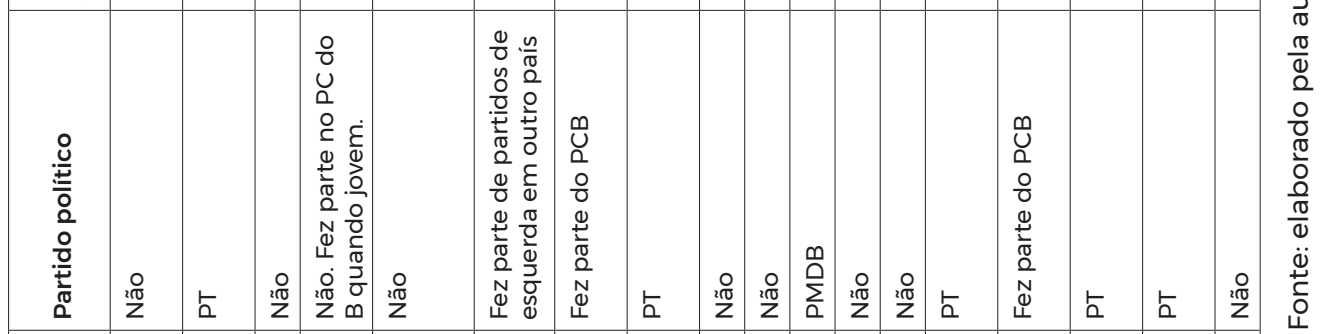

\begin{tabular}{|c|c|c|c|c|c|c|c|c|c|c|c|c|c|c|c|c|c|c|}
\hline 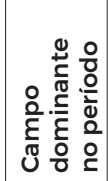 & 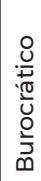 & 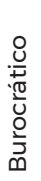 & 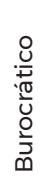 & 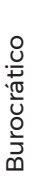 & 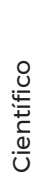 & 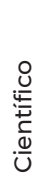 & 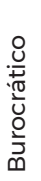 & 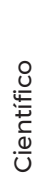 & 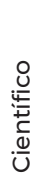 & 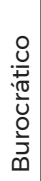 & 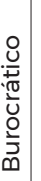 & 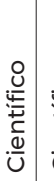 & 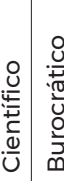 & 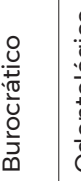 & $\begin{array}{l}\frac{8}{0} \\
\frac{0}{0} \\
\frac{0}{0} \\
\frac{0}{0} \\
0\end{array}$ & 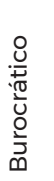 & 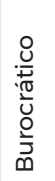 & 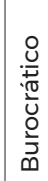 \\
\hline
\end{tabular}

\begin{tabular}{|c|c|c|c|c|c|c|c|c|c|c|c|c|c|c|c|c|c|}
\hline 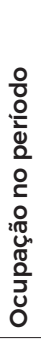 & 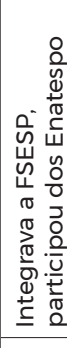 & 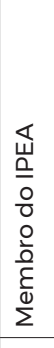 & 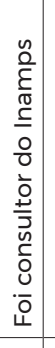 & 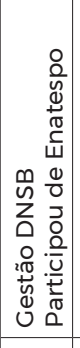 & 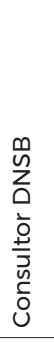 & 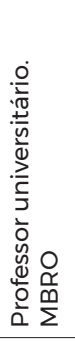 & 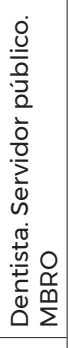 & 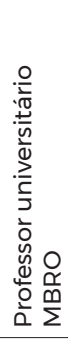 & 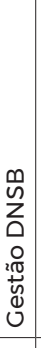 & 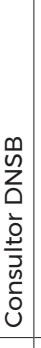 & ' & 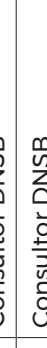 & 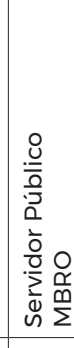 & 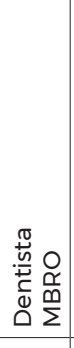 & 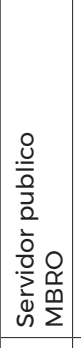 & 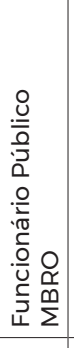 & 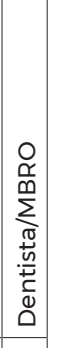 \\
\hline 㸚 & $\begin{array}{l}\dot{u} \\
\dot{\omega} \\
\Sigma\end{array}$ & $\begin{array}{l}\dot{u} \\
\stackrel{\tilde{\sigma}}{\Sigma} \\
\end{array}$ & $\begin{array}{l}\dot{u} \\
\dot{\sigma} \\
\Sigma\end{array}$ & $\begin{array}{l}\dot{u} \\
\sum^{\pi} \\
\Sigma\end{array}$ & $\begin{array}{l}\dot{U} \\
\text { J } \\
\text { IJ }\end{array}$ & $\begin{array}{l}\dot{u} \\
\stackrel{\sigma}{\pi} \\
\Sigma\end{array}$ & $\begin{array}{l}\dot{u} \\
\stackrel{w}{\tilde{\sigma}}\end{array}$ & $\begin{array}{l}\dot{u} \\
\dot{\omega} \\
\dot{\pi}\end{array}$ & $\begin{array}{l}\dot{U} \\
\stackrel{u}{2} \\
\Sigma\end{array}$ & $\begin{array}{l}\dot{u} \\
\Sigma \\
\Sigma \\
\Sigma\end{array}$ & 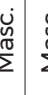 & 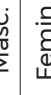 & $\begin{array}{l}\dot{u} \\
\stackrel{\sigma}{\Sigma} \\
\Sigma\end{array}$ & $\begin{array}{l}\dot{u} \\
\stackrel{\tilde{m}}{\Sigma}\end{array}$ & $\begin{array}{l}\dot{u} \\
\sum^{\pi} \\
\Sigma\end{array}$ & 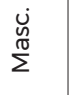 & $\begin{array}{l}\dot{\dot{m}} \\
\dot{m}\end{array}$ \\
\hline 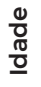 & ৪ & $\bar{\infty}$ & $\stackrel{0}{\sim}$ & $\stackrel{ \pm}{\Sigma}$ & $\stackrel{M}{x}$ & $\kappa$ & 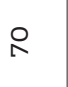 & 8 & \begin{tabular}{c}
$\infty$ \\
$\bullet$ \\
\hdashline
\end{tabular} & 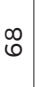 & 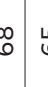 & $\begin{array}{lll}0 \\
0\end{array}$ & $\overline{6}$ & $\stackrel{\infty}{\circ}$ & นก & 员 & \\
\hline 岀 & $\bar{v}$ & $\stackrel{\bullet}{N}$ & $N$ & $\stackrel{N}{ }$ & $\stackrel{\Omega}{\square}$ & $N$ & M & $\stackrel{\infty}{ }$ & 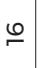 & - & 0 & $\triangle$ & $\stackrel{\circ}{ }$ & $\stackrel{N}{N}$ & $\stackrel{n}{\leftarrow}$ & $\stackrel{\sim}{N}$ & \\
\hline
\end{tabular}


Quadro 8 - Entrevistado, segundo distribuição e volume dos capitais científico, político e burocrático, década de 1980*

\begin{tabular}{|c|c|c|c|c|c|c|c|c|c|c|c|c|c|}
\hline & \multicolumn{4}{|c|}{ Capital Científico } & \multicolumn{4}{|c|}{ Capital Político } & \multicolumn{4}{|c|}{ Capital Burocrático } & \multirow[t]{2}{*}{$\begin{array}{c}\text { Volume } \\
\text { Total }\end{array}$} \\
\hline & $\uparrow$ & $\uparrow \uparrow$ & $\uparrow \uparrow \uparrow$ & $\uparrow \uparrow \uparrow \uparrow$ & $\uparrow$ & $\uparrow \uparrow$ & $\uparrow \uparrow \uparrow$ & $\uparrow \uparrow \uparrow \uparrow$ & $\uparrow$ & $\uparrow \uparrow$ & $\uparrow \uparrow \uparrow$ & $\uparrow \uparrow \uparrow \uparrow$ & \\
\hline E13 & & & & & & & & & & & & & 2 \\
\hline E21 & & & & & & & & & & & & & 2 \\
\hline E16 & & & & & & & & & & & & & 3 \\
\hline E26 & & & & & & & & & & & & & 3 \\
\hline E2 & & & & & & & & & & & & & 4 \\
\hline E19 & & & & & & & & & & & & & 4 \\
\hline E23 & & & & & & & & & & & & & 4 \\
\hline E7 & & & & & & & & & & & & & 5 \\
\hline E2O & & & & & & & & & & & & & 5 \\
\hline $\mathrm{E} 1$ & & & & & & & & & & & & & 6 \\
\hline E3 & & & & & & & & & & & & & 6 \\
\hline E4 & & & & & & & & & & & & & 6 \\
\hline E9 & & & & & & & & & & & & & 6 \\
\hline E10 & & & & & & & & & & & & & 6 \\
\hline E12 & & & & & & & & & & & & & 6 \\
\hline E15 & & & & & & & & & & & & & 6 \\
\hline E22 & & & & & & & & & & & & & 6 \\
\hline E18 & & & & & & & & & & & & & 8 \\
\hline
\end{tabular}

*Legenda: Muito Alto $\uparrow \uparrow \uparrow \uparrow$; Alto $\uparrow \uparrow \uparrow$, Médio $\uparrow \uparrow$, Baixo $\uparrow$, Muito baixo.

Fonte: elaborado pela autora.

O grupo apresentou trajetória ascendente, em sua maioria, tendo cursado o ensino médio em colégios públicos (Quadro 9). No sociograma elaborado em função do capital político e da posição dos agentes na arquitetura do espaço, através de suas tomadas de posição, pode-se observar: na esquerda, encontram-se os indivíduos que defendiam uma posição à época consistente com o projeto da Reforma Sanitária Brasileira, do SUS democrático e de crítica à prática odontológica vigente. À direita, estão posicionados os dentistas que ocupavam cargos nos CFO e ABO e tomavam posições ligadas à defesa da Odontologia liberal, contrárias à proposta da inserção de pessoal auxiliar e apoio às políticas de saúde que poderiam representar benefício aos profissionais da Odontologia (Figura 9).

No centro do sociograma, na posição do governo, estão os coordenadores de Odontologia do Inamps e o diretor da DNSB do Ministério da Saúde com tomadas de posição relacionadas à Odontologia Sanitária/Social, além do trabalho dos técnicos e assessores, que estão situados mais à direita ou à esquerda, a depender de suas tomadas de posição e do capital político acumulado. 


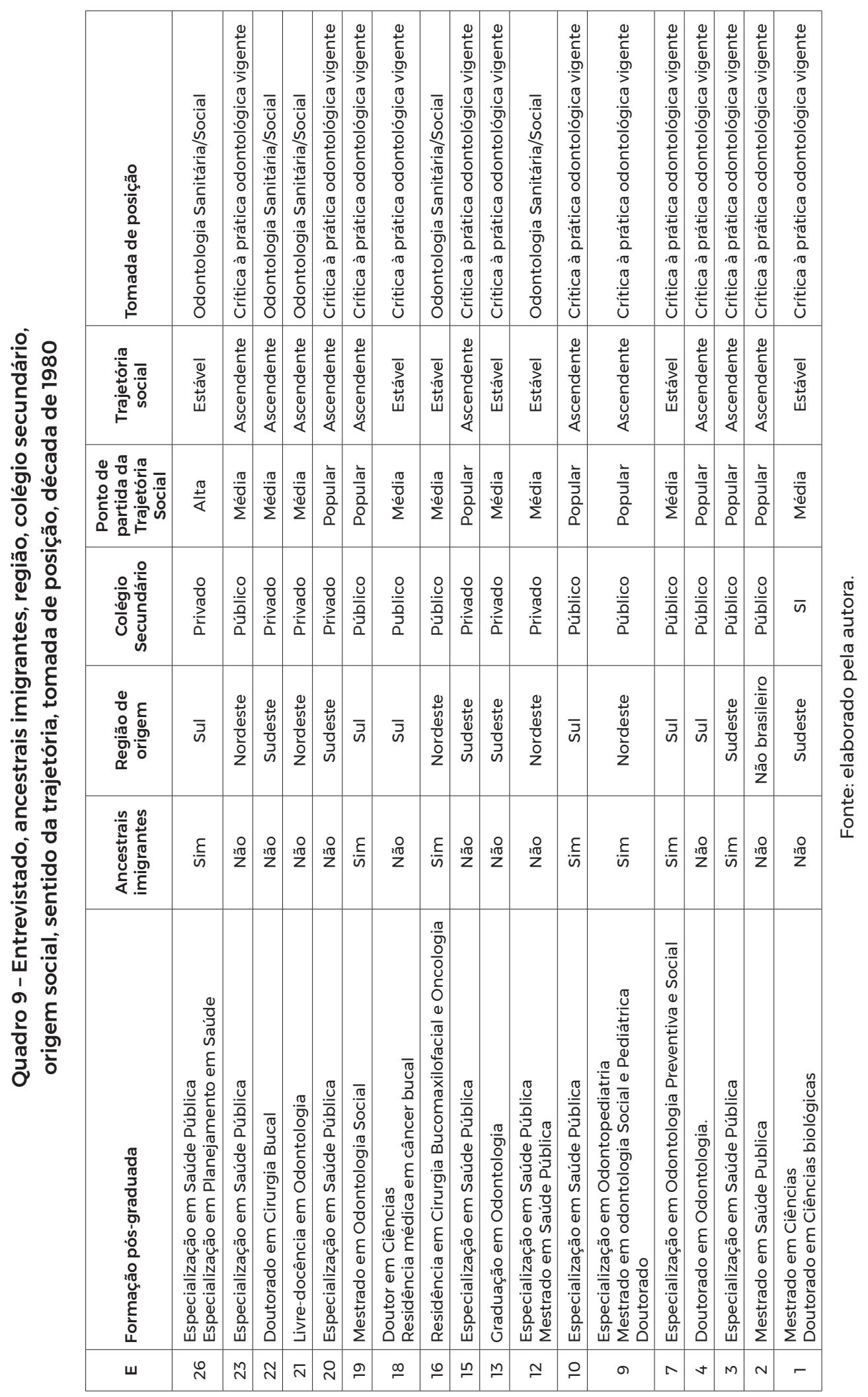


Embora haja uma variada combinação das três espécies de capital analisadas, pode-se dizer que a posição da Aboprev é mais relacionada ao alto capital científico, enquanto a da DNSB com a acumulação de capital burocrático e o do MBRO a um elevado capital político (Figuras 6, 7 e 8). Destaca-se que a palavra mais frequente de quatro e cinco letras foi "saúde", estando "bucal” em segundo plano (Figura 10), o que pode ser justificado pelo cenário sociopolítico econômico no qual se lutava pela democracia e pela saúde, estando a saúde bucal incluída nas políticas de saúde.

Alguns autores como: Chaves (1986), Pires (2004), Narvai e Frazão (2008b), Moysés e Goes (2010) e Moysés (2014), analisaram o conceito do termo saúde bucal. Chaves (1986) considera que este conceito é uma abstração útil. O autor relaciona a utilização do termo para efeitos práticos, significando saúde parcial (bucal), servindo para identificar objetivos parciais em programas de saúde. Justificou a utilização do termo em seu livro Odontologia social, em substituição de saúde dentária, devido ao reconhecimento da responsabilidade do dentista, àquela época, de ir além dos dentes, contemplando as estruturas adjacentes que os suportam e certas porções da cavidade bucal. Reiterou que a saúde bucal em estado de harmonia, normalidade ou higidez da boca só teria significado quando acompanhada da saúde geral do indivíduo assim como os programas especializados quando integrados em um programa global de saúde pública. Aqui, observa-se uma restrição do objeto da saúde bucal aos dentes, suas estruturas de suporte e partes da boca. É possível observar, também, a utilização do termo saúde oral em publicações, inclusive aquelas do MBRO. Destaca-se que o mesmo texto descrito foi utilizado para conceituar "saúde oral" no livro Odontologia Sanitária, do mesmo autor, em 1960. Nesse sentido, houve apenas uma mudança dos termos "oral” para "bucal”, significando exatamente o mesmo, sem explicitação dos motivos que conduziram a esta mudança.

As Conferências Nacionais de Saúde também abordaram o conceito de saúde bucal, mas de modo abrangente, enquanto parte inseparável da saúde geral do indivíduo, relacionando-se às condições de moradia, alimentação, trabalho, renda, meio ambiente, transporte, lazer, liberdade, acesso e posse de terra, acesso aos serviços de saúde e à informação. (BRASIL, 1986b) Outro trabalho confrontou a definição de Chaves (1986), afirmando que

[...] saúde bucal corresponde a um conjunto de condições objetivas (biológicas) e subjetivas (psicológicas), que possibilitam ao ser humano exercer funções como mastigação, deglutição e fonação e, também, pela dimensão estética inerente à região anatômica, exercitar a autoestima e relacionar-se socialmente sem inibição ou constrangimento. Estas condições devem corresponder à ausência de doença ativa em níveis tais que permitam ao 
indivíduo exercer as mencionadas funções do modo que lhe pareça adequado e lhe permita sentir-se bem, contribuindo desta forma para sua saúde geral. (NARVAI; FRAZÃO, 2008b, p. 18)

Os autores ampliam o conceito de saúde bucal relacionando-o não apenas a estruturas anatômicas, mas a condições também subjetivas, às funções desempenhadas em sua vida e à relação com o sentir-se bem. Ressalta-se, também, que bem-estar é o termo utilizado pela Organização Mundial de Saúde (OMS) para tratar de saúde bucal enquanto parte da saúde geral, essencial para o bem-estar das pessoas. (NARVAI; FRAZÃO, 2008b) Outro trabalho ratifica esse ponto de vista, afirmando que adotar este ideário significa ultrapassar o pensamento hegemônico sobre saúde/doença bucal que advém da visão etiopatogênica e epidemiológica negativa, baseada no diagnóstico normativo das doenças, em suas manifestações clínicas enquanto sequelas terminais.(MOYSÉS; GOES, 2010) Esses autores também analisaram a utilização do termo relacionando-o às práticas de controle social assim como à organização dos serviços públicos, dentre outros. Já Pires (2004) utilizou o conceito de saúde bucal da I CNSB para analisar a Política Brasil Sorridente.

A palavra mais frequente com seis letras ou mais, sete ou mais até dez letras, foi "Odontologia", que apresenta diversas adjetivações e movimentos teóricos que a caracterizam. (NARVAI, 1994) Tendo em vista que os objetivos das diversas políticas analisadas até os anos 1990 priorizaram o controle da cárie dental, há uma dissociação entre o discurso e as práticas.

Figura 6 - Agentes participantes do espaço de formulação de crítica das políticas de saúde bucal, segundo capitais burocrático e científico, década de 1980

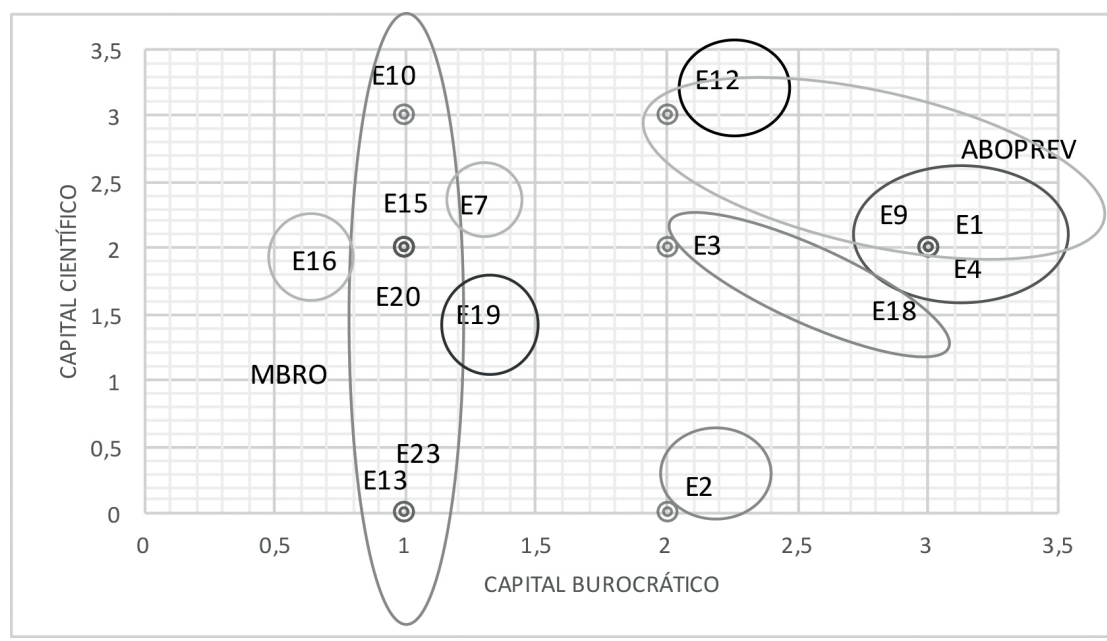

Fonte: elaborada pela autora. 
Figura 7 - Agentes participantes do espaço de formulação de crítica das políticas de saúde bucal, segundo capitais burocrático e político, década de 1980

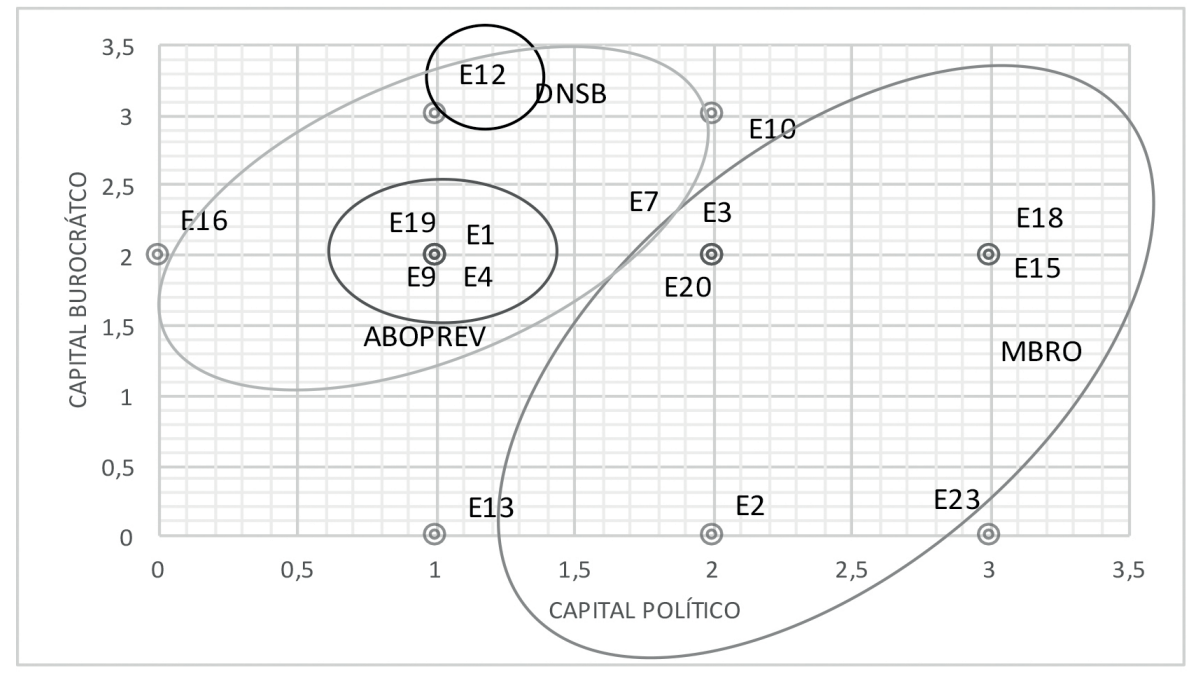

Fonte: elaborada pela autora.

Figura 8 - Agentes participantes do espaço de formulação de crítica das políticas de saúde bucal, segundo capitais político e científico, década de 1980

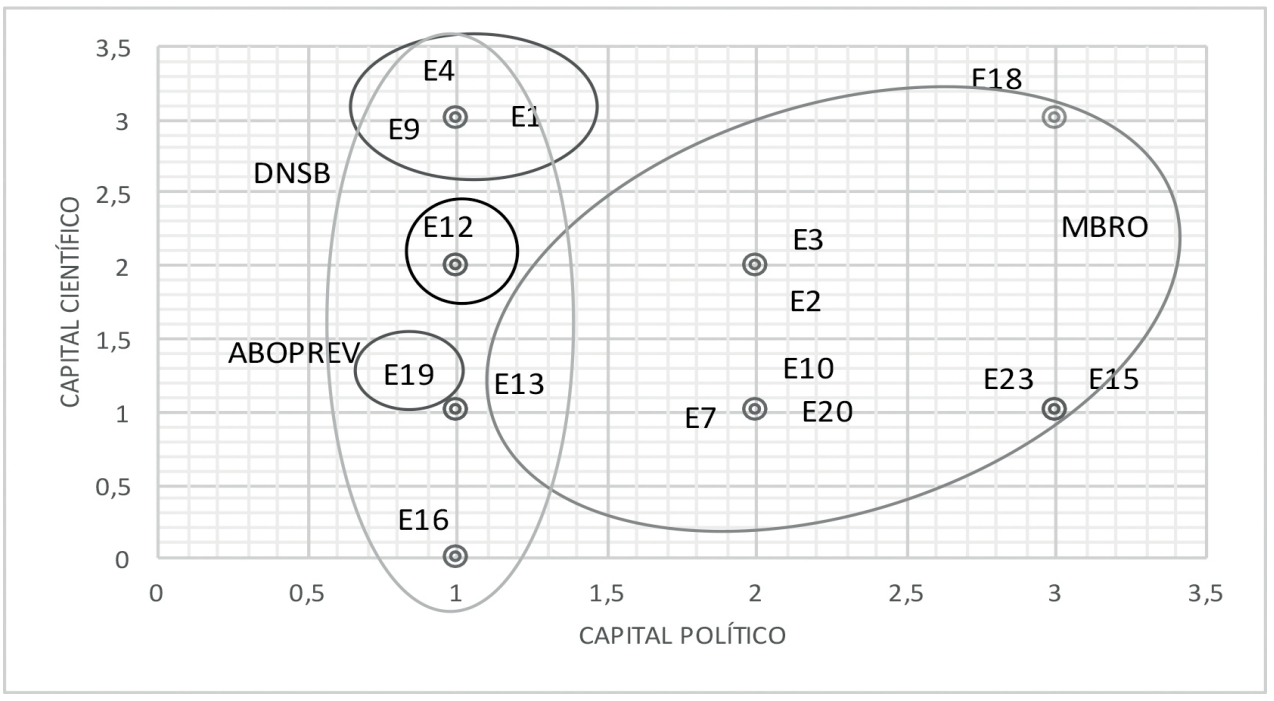

Fonte: elaborada pela autora. 


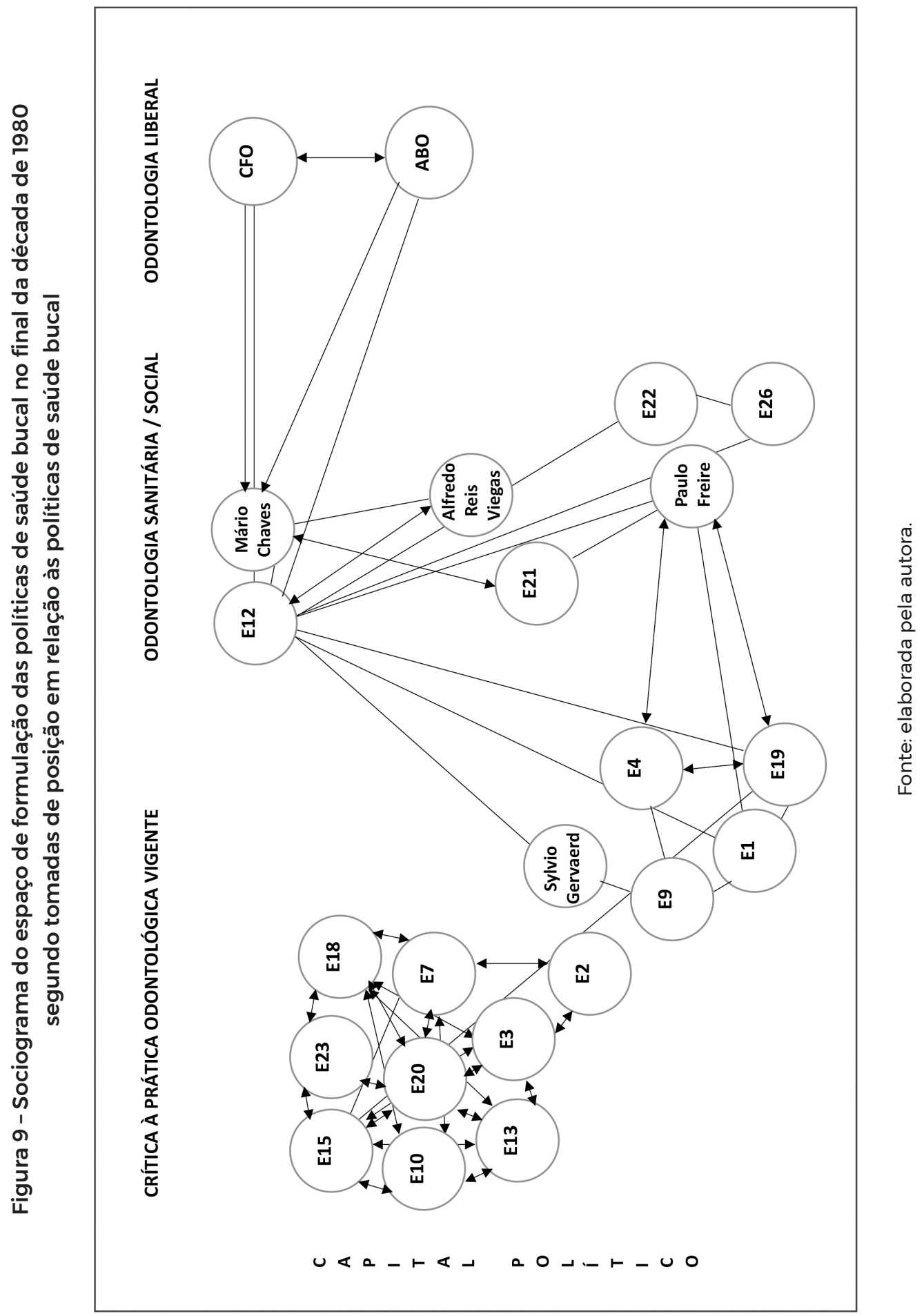

Produção Social da Políticas de Saúde Bucal no Brasil / 109 
Figura 10 - Palavras mais frequentes a partir de cinco, seis, sete, oito, nove e onze letras, respectivamente
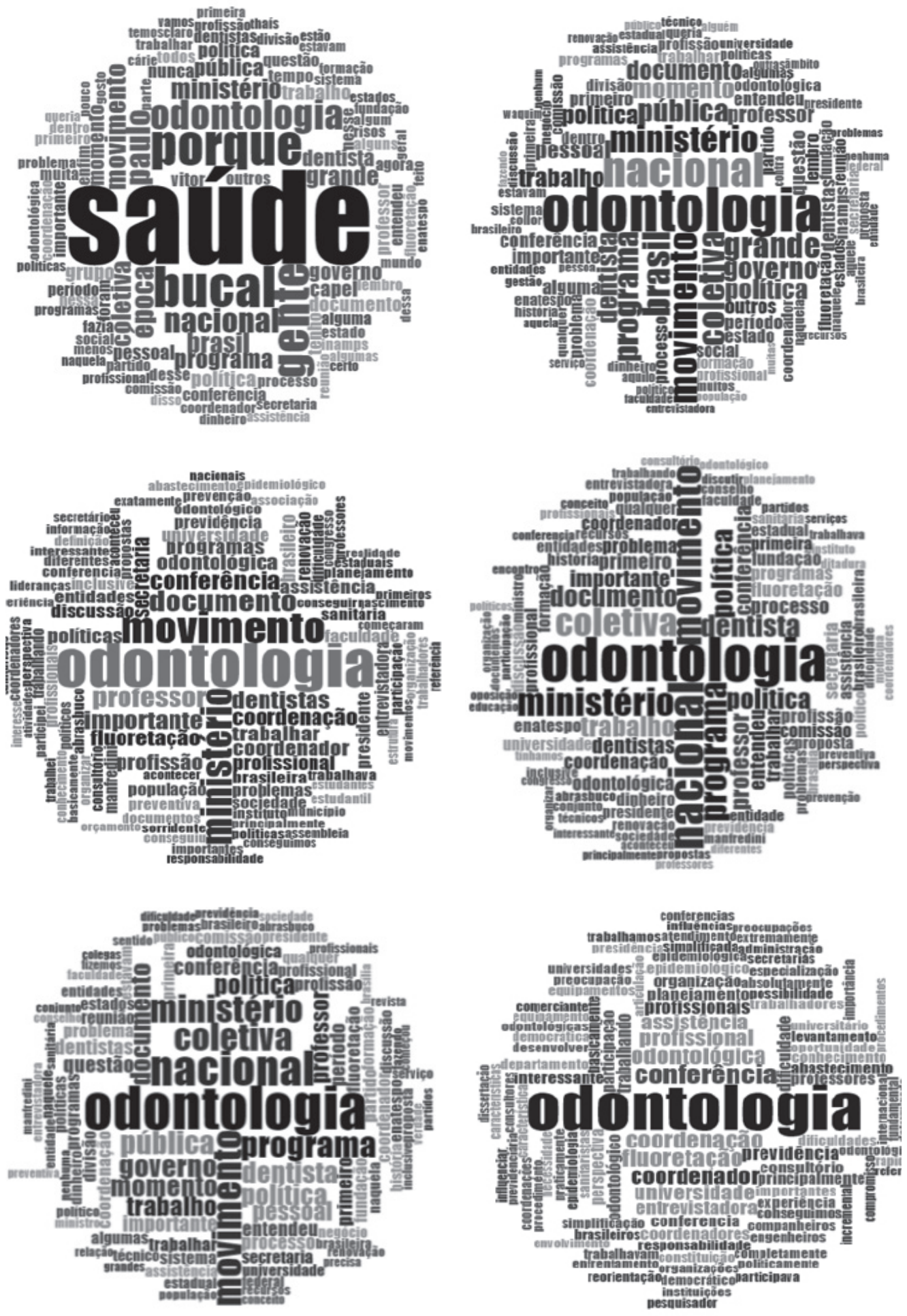

Fonte: elaborado pela autora. 